\title{
Physical Aspects of Geothermal Energy
}

Geothermal energy is an economic alternative to fossil fuels and even hydroelectric energy in many parts of the world. The goal is to extract heat from a geothermal reservoir (Fig. 1), where the hydrothermal fluid serves as carrier for the thermal energy to be mined. The first systems to be exploited were vapour-dominated systems, yielding steam for the generation of electricity, and hot groundwater systems delivering water for space heating. The most common type of reservoir exploited in recent years is the liquid-dominated type, which under utilization develops into a boiling reservoir. Interest is growing in experiments to extract heat from hot, impermeable rocks by controlled hydraulic fracturing and injection of fluid to carry the heat to the surface. Similar ideas are being developed for heat extraction from magma bodies.

Geopressured geothermal reservoirs have been found in association with petroleum reservoirs; submarine geothermal systems have been discovered, rich in metals and minerals. Although these systems are unlikely to be exploited for heat energy, their investigation may cast light on the processes that govern the formation of metalliferous deposits in the roots of continental geothermal systems. This great variety in geothermal phenomena shows that the physical processes of interest are not limited to subcritical temperatures and pressures, but may range to magmatic temperatures and lithostatic pressures at a depth of about $10 \mathrm{~km}$.

Exploration of reservoir rocks yields basic information on physical properties and defines the physical state of a geothermal resource. We believe today that magma is the primary heat source of geothermal reservoirs, and that water from the atmosphere or from the oceans penetrates the solidifying crust of magma bodies and transports heat to the Earth's surface by convection and boiling. Understanding of this nature is introduced into conceptual models which form the basis for reservoir assessment. This process usually involves a numerical model of the natural state of the reservoir, before withdrawal of fluid affects it physically, as well as modelling to predict the response of the reservoir to exploitation and to estimate the production capacity of the geothermal

Sveinbjörn Björnsson is Rector of The University of Iceland, 101 Reykjavik, Iceland. After receiving a diploma in physics from the RWTH Aachen in 1963, he worked with the Icelandic National Energy Authority on geothermal exploration and resevoir assessment for 10 years before joining The University of Iceland. Appointed professor in geophysics in 1978, he has acted as a geothermal consultant to the United Nations and to governments in Africa and Central America.

\section{S. Björnsson}

\author{
The University of Iceland, Reykjavik, Iceland
}

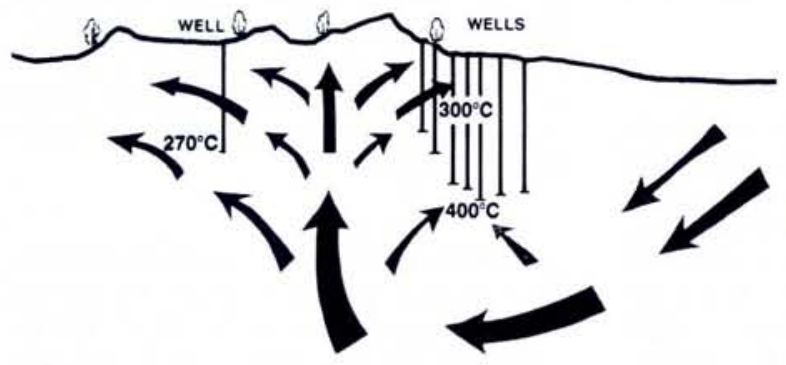

Fig. 1 - A conceptual flow model of the Hengill geothermal region in Iceland. Rainfall seeps into volcanic rocks and finds its way to the bottom of the geothermal system. There the water is heated by contact with hot intrusive rocks and ascends, boiling. (Courtesy of Reykjavik District Heating.)

resource. Our aim, therefore, is to discuss the fundamental physical principles that underlie much of what is known about geothermal reservoirs and their exploitation.

\section{Source of the Fluid}

In geothermal reservoirs, heat is mainly transported by a hydrothermal fluid consisting of liquid water with solids, water vapour, and gases dissolved in the liquid and free in the vapour. Generic types of water are [1] water recently involved in atmospheric circulation (meteoric water); water penetrating into the crust of ocean-floor spreading centers (ocean water); "new" water from mantlederived magma and which has not previously been part of the hydrosphere (juvenile water); water derived from magma, but not necessarily juvenile water, since magma may incorporate meteoric or ocean water of deep circulation, or water from sedimentary material (magmatic water); "fossil" water incorporated in sediments of the time of deposition (connate water); modified connate water, derived from hydrous minerals during their recrystallization to less hydrous minerals during metamorphic processes (metamorphic water).

Systematic studies of stable oxygen and hydrogen isotopes in geothermal water have established meteoric water to be the dominant source of fluid in most active continental geothermal systems. It is also well established that hydrothermal circulation plays a major rôle in the thermal balance of ocean ridges where ocean water is the dominant fluid source. The contribution of magmatic or juvenile water appears to be minimal, but there is growing evidence for magmatic influence on thermal fluids (see below).

Differentiating between meteoric and ocean water might seem to be of little importance, but for the fact that the chemical composition of ocean water has a large effect on the solvent action of the geothermal fluid.
When seawater is heated within a rock matrix, removal of magnesium from the seawater generates acidity which maintains heavy metals in solution at moderate temperatures (about $300^{\circ} \mathrm{C}$ ). This acidity, and the higher hydrostatic pressure, influences the chemical output of submarine geothermal systems towards much higher metal concentrations as compared to geothermal systems fed by meteoric water.

\section{Magma as a Heat Source}

A frequently cited model of large-scale circulation of fluid in the natural state of a geothermal system is illustrated in Fig. 2 [2]. Cold groundwater percolates down faults, dykes, and fissures to considerable depth, where it picks up heat in permeable hot rocks. The density difference between the cold and the hot water results in buoyancy imbalance, which drives the hot water back to the surface along permeable channels. The heat source may be a magma chamber at greater depth, or simply the general heat flow from the Earth's interior. The latter represents, e.g., so-called low-temperature

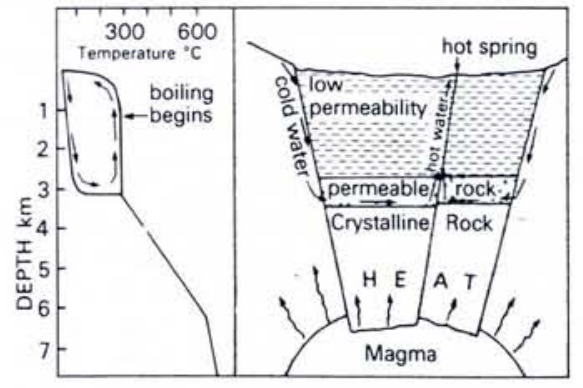

Fig. 2 - Model by White [2] of the largescale circulation of fluid in the natural state of a geothermal system. Cold water percolates down down faults, dykes and fissures to considerable depth. The heat source may be a magma chamber (as in the figure) or general heat flow from the Earth's centre. 
systems where the temperature at the base of circulation, $T_{\max }$, is generally $<150^{\circ} \mathrm{C}$.

Of the numerous speculations about the nature of thermal activity, the work of Einarsson [3] represents the first quantitative treatment. He contended that the hot springs of Iceland were not physically different from ordinary cold springs, except for the greater depth of penetration of the water; heat simply came from the conductive heat flux from the interior of the Earth. Bodvarsson [4] elaborated this concept further. He agreed with Einarsson on the nonvolcanic origin of low-temperature fields $\left(T_{\max }<150^{\circ} \mathrm{C}\right)$, but concluded from energy balance considerations that the conduction process involved in the heating must be of a transient nature.

\section{Thermal cracking}

Noting that there is a strong positive correlation between temperature and mass flow of the geothermal system, Bodvarsson [5] further concluded that convective downward migration of fracture spaces along the walls of feeder (so-called mafic) dykes appeared to be a dominant thermomechanical process in the development of the low-temperature systems. Convective fluid motion in open vertical fracture spaces is associated with the withdrawal of heat from the formation at the lower boundary of the reservoir, resulting in thermoelastic contraction of the adjacent rock and opening of additional fracture spaces at the bottom. A single fracture or system of fractures harbouring such convective fluid motions can therefore migrate downward by the process. Since the walls of dykes are not welded to the surrounding country rock, the downward migration process does not involve thermoelastic fracturing of solid rock.

The intense heat output of the high-temperature steam fields (of the order of 100$1000 \mathrm{MW}$ thermal over periods of $10^{4}$ years) cannot be explained by the normal conductive heat flux of Earth. The concentrated source of heat must be magma or hot, recently solidified rock. Limited surface area and slow thermal conduction through solid rock require intimate contact between the rock and the percolating fluid.

A conceptual model of the downward penetration of water into hot rocks by a process of cooling and thermal cracking has been presented by Lister [6]. Evidence in support of water penetration into hot rock boundaries of solidifying magma was reported by Björnsson et al. [7], who concluded that this process of heat extraction is required to explain the sustained heat output of $5000 \mathrm{MW}$ of the Grimsvotn geothermal area under the Vatnajokull ice-cap in Iceland. Submarine systems such as the hydrothermal vents jetting out water at $380^{\circ} \mathrm{C}$ along the axis of the East Pacific Rise at a water depth of 2500 to $2900 \mathrm{~m}$ [8] may also be regarded as evidence for convective downward migration of water into oceanic crust.

\section{Convection in the magma}

White [9] found that a magma supply of at least $10^{2}-10^{3} \mathrm{~km}^{3}$ in size was required to support the Steamboat Springs geothermal system in the USA through its life of $10^{5}-10^{6}$ years. $\mathrm{He}$ argued that a magma body intrud-

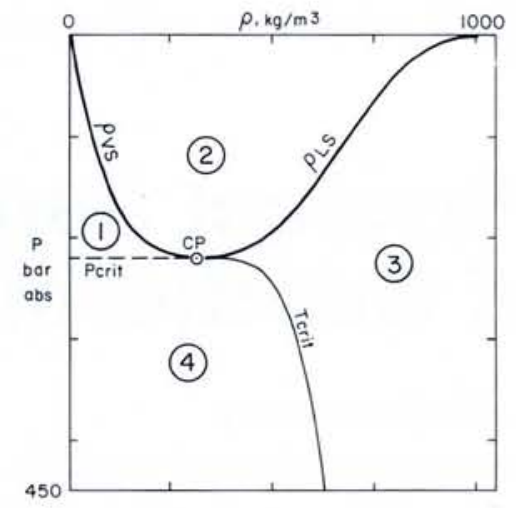

Fig. 3-Physical states in hydrothermal systems [11]. Indicated are: the vapour saturated region (1); the boiling region (2) enveloped by Clapeyron curves through the critical point; the liquid-saturated region (3); the supercritical region (4).

ing into the shallow crust, and then remaining static as it cools and crystallizes, is not a satisfactory model unless the fissure system controlling the circulating water can gradually extend deeper into the body while stored heat is removed at higher levels by circulating water. As an alternative for the heat-flow problem, he suggested convection within the magma chamber to maintain temperatures at the normal magma level near the base of the hydrothermal circulation.

Irvine [10] has studied the relation between temperature in a magma body and a crystallization mechanism for which crystal separation is a major process. He described a convection process in the magma body where crystals are accumulated in the lower part of the intrusion, but the temperature near the top remains close to or above the liquidus temperature of the magma. This process allows higher rates of heat loss and solidification than would occur if the crystals were frozen to the roof of the magma chamber. Convective processes of this nature appear to be capable of providing sufficient heat transfer to the hydrothermal fluid to explain the heat output of most geothermal systems.
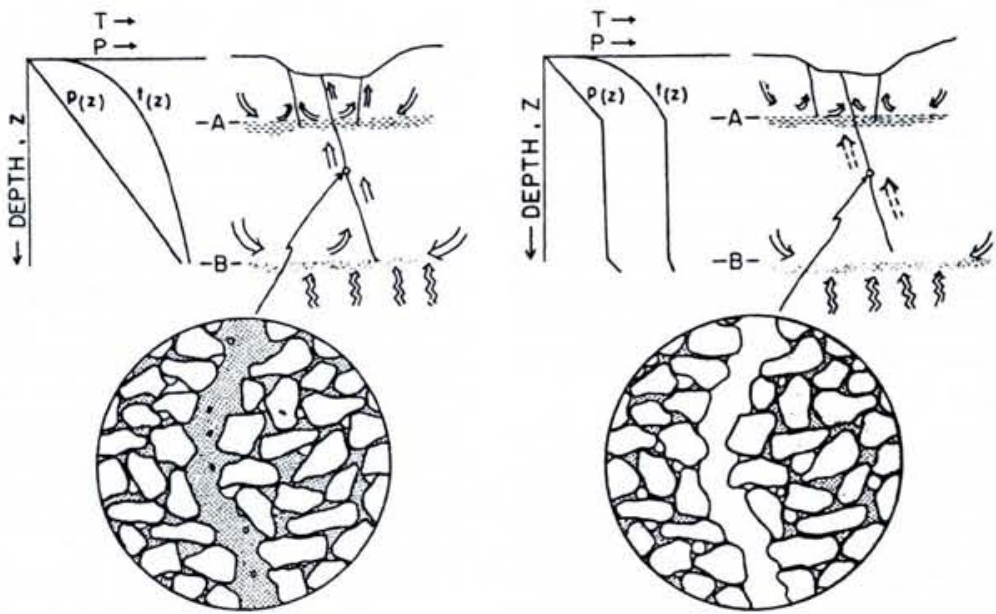

Fig. 4 - Fluid distribution in pores and fractures (after [12]). left) Liquid dominates the open channels, although bubbles of steam and gas are present. right) Vapour dominates in the open channels, but liquid fills most of the intergranular pore space.
To summarize, one may conclude that the heat source of the major geothermal systems is magma. The intense loss of heat observed in some geothermal fields is, however, difficult to explain. One possibility is that heat transfer from the magma to the hydrothermal fluid is brought about by downward penetration of water and cracking of the hot intrusion. Alternatively, convection is taking place within the magma body in such a way that the boundary between the magma and the hydrothermal fluid remains relatively thin for a considerable time.

Physical States of Geothermal Systems

There have been many attempts to define basic types of geothermal systems. The classification chosen here is by the physical state of the reservoir fluid [11]. Geothermal systems are generally complex and contain zones representing different physical states. Fig. 3 uses the temperature $T$, pressure $P$, and density $\rho$ of the reservoir fluid to recognize four regions separated by the Clapeyron curves for saturated vapour and liquid; the critical isothermal $T_{\text {crit }}$ for $P>P_{\text {crit }}$ and the critical isobar $P_{\text {crit }}$ for $T>T_{\text {crit. }}$ In three of the regions, the thermal fluid occurs as a single phase.

The liquid-saturated region contains the class of geothermal systems where the temperature never reaches boiling. Most important of these are hydrothermal systems in the ocean crust. Hydrothermal circulation at hydrostatic pressures exceeding the critical pressure for the fluid will not reach boiling, unless it is induced by the release of volatile compounds from geothermal fluid. These pressures are found beneath oceans of 2.2 $\mathrm{km}$ depth. Hydrothermal circulation in the ocean crust is thus generally a single-phase convection of seawater.

Geothermal systems belonging to the vapour-saturated region are found on active volcanoes, and low pressure superheated steam is common at shallow depths in geothermal fields. Exploitation also leads to drying out of water in vapour-dominated rocks near production wells.

Supercritical conditions are expected in geothermal systems that penetrate deep into the crust to supercritical pressures, 


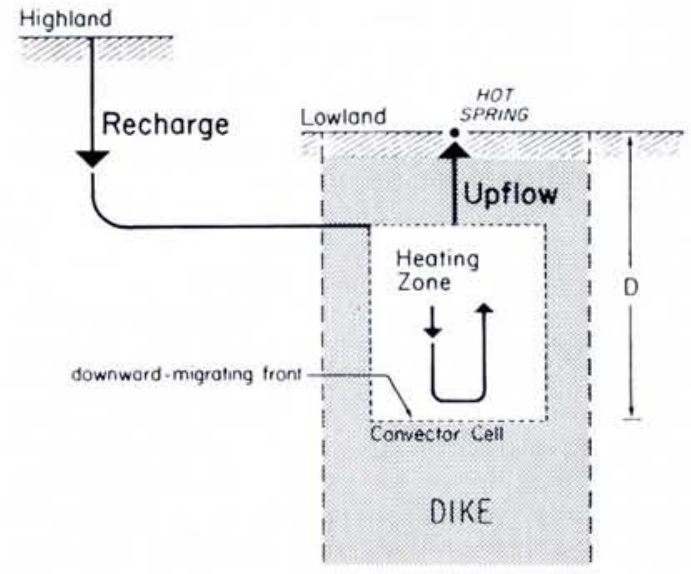

where young igneous intrusions have generated supercritical temperatures. On land, these conditions could be found below 3.5 $\mathrm{km}$ depth in the crust, assuming boiling conditions in the hydrostatic fluid above. On the sea floor, the hydrostatic head of the ocean may exceed the critical pressure, and supercritical temperatures can therefore exist at shallow depth beneath the floor.

The most important region for the discussion of geothermal systems is the twophase boiling region enveloped by the Clapeyron curves at subcritical temperatures and pressures. An additional parameter such as the water saturation, i.e., the volume fraction $S$ of water in the fluid, is needed to uniquely define physical conditions within this region (see below). Physical states with intermediate mixtures of liquid and vapour are not stable, although they may exist as transient phenomena. Gravity segregation of the phases leads to separation of the reservoir into a lower zone with high water saturation and a pressure gradient dominated by liquid density, and an upper zone with low water saturation where vapour density controls the vertical pressure gradient.

Geothermal reservoirs are often referred to as either liquid-dominated or vapourdominated, depending on the phase which controls the vertical pressure gradient (Fig. 4). The former are either liquid-saturated or boiling with a small vapour saturation; the vapour-dominated either vapour-saturated or boiling with a high vapour saturation. Most known geothermal reservoirs are of the liquid-dominated type, although vapour-
Fig. 5 - Dyke convector model [5]. Water recharge enters a dyke via a relatively shallow path and then sinks through cracks or fissures along the walls of the dyke where it takes up heat; convection within the dyke transports heat upwards.

dominated fields have been favoured for the generation of electricity.

\section{Conceptual Models}

The frequently cited model for the largescale circulation of fluid in the natural state of a geothermal system shown in Fig. 2 assumes cold groundwater percolates to considerable depth, where it picks up heat in permeable hot rocks. This has been modified in the dyke convector model (Fig. 5) which assumes that the recharge enters a dyke along some relatively shallow path, but sinks through cracks or fractures along the walls of the dyke, where it takes up heat from the hot adjacent rock [4]. Convection within the dyke transports heat from lower lying rocks and delivers excess heat to the upper layers. In this way, the convection is able to equalise the temperature within the convector.

\section{Boiling point curves}

As water in a liquid-saturated reservoir ascends to lower pressure, it eventually reaches saturation pressure and begins to boil (Fig. 2). Below the boiling level, the temperature is practically constant and equal to the base temperature; above the boiling level, the temperature and pressure are related by the Clapeyron curve for saturated liquid. Ignoring the dynamic pressure drop caused by the upflow, usually less than $10 \%$ of the static gradient, the temperature and pressure in the rising column may be estimated by summing up the static weight of a column of water whose temperature is everywhere at saturation for the local pres-
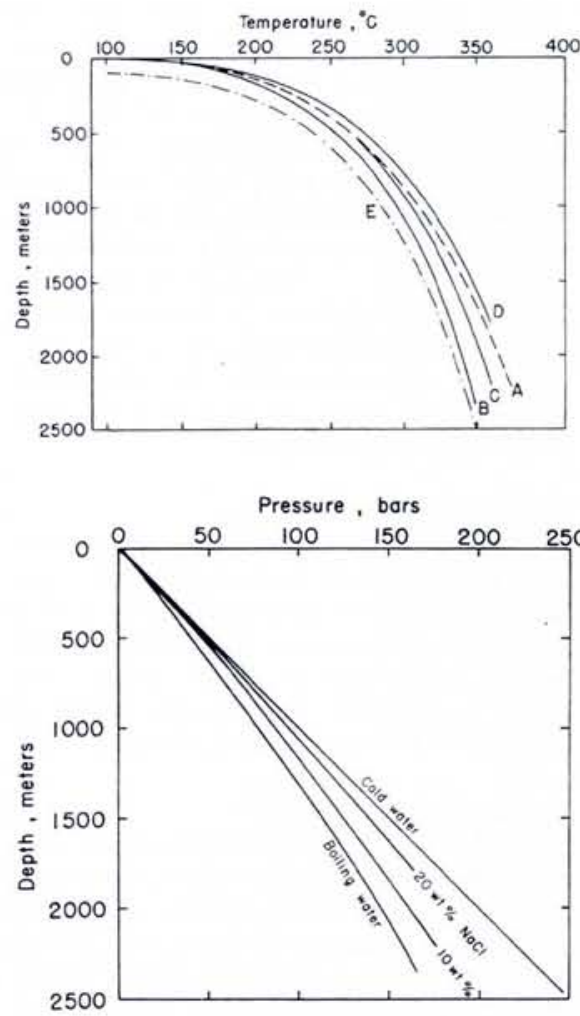

Fig. 6 - Depth-temperature (a, upper) relations for boiling solutions, and depth-pressure $(b$, lower) relations for cold and boiling solutions (after [13]).

sure. Examples of such boiling point curves are given in Fig. 6 . If non-condensible gas is present, its partial pressure adds to the vapour pressure and initiates boiling at a higher local pressure than for pure water (Curve $\mathrm{E}$ in Fig. 6a).

\section{Upflow regions}

Exploration of geothermal systems is usually limited to the exploitable part of the reservoir, namely the region of upflow. Most conceptual models therefore only describe this part of the system. Representations (Fig. 7) of conceptual models of upflow regions in liquid- and vapour-dominated systems illustrate that the natural state and the initial fluid distribution are controlled by a dynamic balance of mass and heat flow.
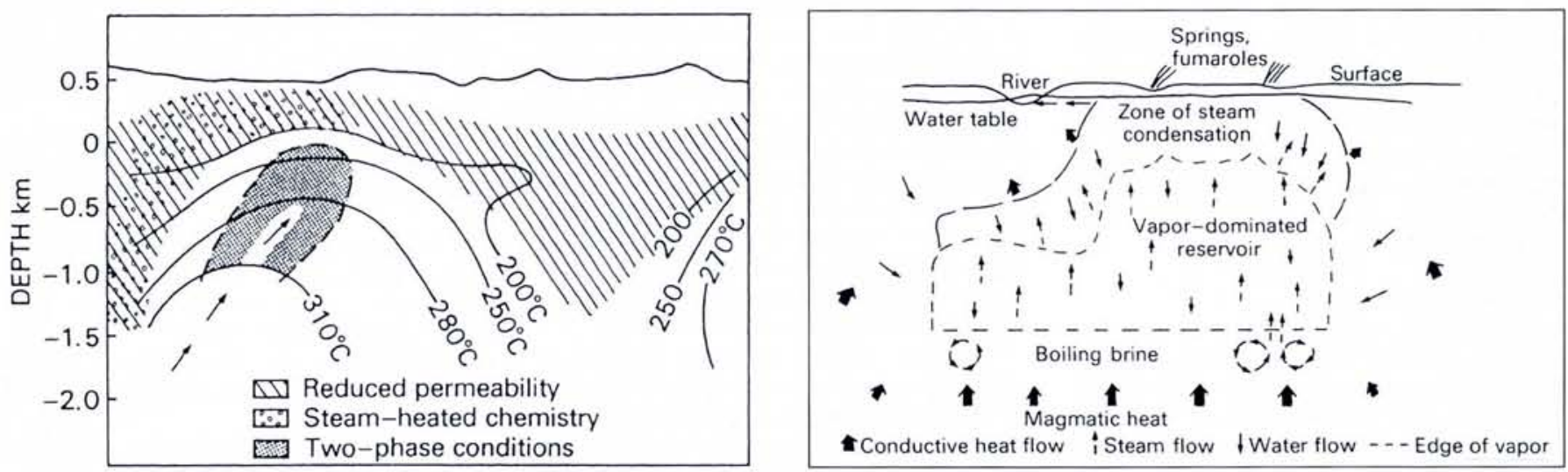

Fig. 7 - Conceptual models of upflow regions. left) Liquid-dominated system: section through the Tongonan reservoir, The Philippines: an outer region containing liquid water encompasses most of the field. right) Vapour-dominated system: model of fluid flow in the natural state (from [18]). 
For vapour-dominated reservoirs, the main part of the reservoir is defined by vapour ascending from a layer of boiling convecting brine. At the top of the reservoir, impermeable cap rock prevents escape of the steam so heat is lost to the surface and boundaries by conduction. This heat loss is balanced by the condensation of steam and the condensate trickles against the rising steam down to the brine. In this counterflow of steam and condensate, the steam occupies the wider channels but the water favours small pores and channels because of its high surface tension.

\section{Convection and Boiling}

Thermal convection is a fundamental process of heat transport in hydrothermal systems. Although single-phase convection of water has received the most attention, twophase convection of water, steam and gases is probably the dominant mode of convection in most geothermal reservoirs.

\section{Single-phase convection}

A linear stability analysis shows that thermal convection in a liquid-saturated porous layer is initiated when a critical value of the Rayleigh number, $R a$, is exceeded. In a horizontal layer of thickness $H$ and a temperature difference $\Delta T$ across the layer, the Rayleigh number can be expressed as

$$
R a=\alpha g \Delta T H \rho^{2} c_{p} K / \mu \lambda
$$

where $\alpha$ is the coefficient of thermal expansion of the fluid, $g$ the acceleration due to gravity, $\rho$ the fluid density, $c_{\mathrm{p}}$ the specific heat of the fluid at constant pressure, $K$ the permeability of the rock, $\mu$ the dynamic viscosity of the fluid, and $\lambda$ the thermal conductivity of saturated rock. The most common approximation is to take $c_{\mathrm{p}}, K, \mu, \lambda$ and $\alpha$ as being constant; density variations are included in the buoyancy term of the vertical balances of forces, but otherwise density is assumed to be constant.

The conditions for the onset of thermal convection in a water-saturated porous layer have been studied by Straus and Schubert [14]. Using an accurate representation of the equation of state for liquid water and an empirical formula for the viscosity of water as a function of temperature and pressure, they fourid that the permeability needed for convection is seriously overestimated when the thermal properties of water are assumed to be constant. Owing to the effects of variable water properties, convection can occur for smaller vertical temperature differences in rock of a given permeability, or for a smaller permeability at a given temperature difference. This enhancement of convection is mainly promoted by the substantial increase of thermal expansivity and the decrease of viscosity with increasing temperature.

\section{Two-phase convection}

The flowing water in many geothermal systems reaches the saturation pressure due to release of pressure, whereupon boiling begins. The fluid becomes a two-phase mixture of steam and water with thermodynamic and transport properties different to those of liquid water. Where steam and water are in thermodynamic equilibrium, the fluid temperature and pressure are related by the Clapeyron equilibrium equation which determines the boiling (Clapeyron) curve separating the steam and water phases on a P-T diagram: the thermodynamic properties of each phase are unique functions of temperature (or pressure) only. The twophase flow is generally assumed to be laminar, but this assumption might not be valid if rapid boiling occurs.

Darcy's law is generally applied separately to the steam and water phases by introducing relative permeability factors to account for the restricted flow of each phase in the presence of the other. These factors, expressed as functions of the volume fraction of each phase, remain today poorly defined and important values such as the water saturation at which the water becomes immobile, are inadequately known.

In view of the difficulties met in defining the relative permeability, the use of complex relationships is hardly warranted. One often simply assumes that the relative permeability factor for each phase is equal to the saturation value of the respective phase. The Darcy flow of either phase is driven by the pressure gradient in excess of their respective static gravity gradients. However, effects caused by critical behaviour, dissolved gases, relative flow, and the presence of a porous medium must also be allowed for.

Many properties of the fluid change rapidly as the thermodynamic critical point is approached and the expected significant increase in heat transfer rate near this point has been observed [15]. The presence of gases in geothermal fluids usually greatly enhances convective instability. Analyses of the one-dimensional steady upflow of hot water show that only liquid water exists at all depths for flow rates below a critical value; three zones consisting of a near-surface water layer, an underlying two-phase zone of water undergoing pressure release boiling, and a deeper zone of liquid water exist above the critical value [16].

Onset of convection in a three-dimensional porous medium containing a steamwater mixture of water at saturation temperature at all depths is quite different to that for an ordinary single-phase fluid. This is because the ordinary Rayleigh instability is driven by buoyancy forces which cause relatively hotter, lighter fluid elements to rise and relatively colder, heavier fluid parcels to sink [17]. The two-phase convection in effect proceeds by way of a phase change instability mechanism associated with the requirement that $T$ and $P$ lie on the Clapeyron curve. A perturbed hotter region of the fluid is also at a higher pressure than its surroundings, and fluid will flow horizontally away from the hot spot. Conservation of mass then requires a vertical inflow of fluid; condensation and boiling occur to achieve a balance of flow in the vertical direction.

The most striking aspects of this type of convection are the small lateral dimensions of the convection cells and concentration of the flow, phase changes, and temperature variations toward the bottom of the porous layer. The cells are only about half as wide as those of ordinary buoyancy-driven con- vection in water; two-phase cells are even narrower, and the flow more concentrated toward the bottom. This phase change instability mechanism induces convection prior to the onset of ordinary bouyancydriven thermal convection.

\section{Steam-water counterflow}

in vapour-dominated systems

In the discussion of single-phase and twophase convection above, it has implicitly been assumed that water is the continuous phase throughout the system, and thus provides control. Pressure in such systems is near hydrostatic values. This appears to be the most common state of a geothermal reservoir. There are, however, important exceptions, such as the vapour-dominated reservoirs, where the steam is the continuous, pressure-controlling phase, although liquid water is also present. An essential feature of a two-phase, vapour-dominated system is the counterflow of rising steam and descending water, where the large density difference provides a driving force that tends to segregate the two phases.

[1] White D.E., Geol. Soc. Am. Bull. 68 (1957) 1637; White D.E., idem. 68 (1957) 1659; White D.E., Econom. Geol. 6 (1974) 954; Ellis A.J. \& Mahon W.A.J., Chemistry \& Geothermal Systems (Academic Press) 1977

[2] White D.E., Am. J. Sci. 265 (1967) 641.

[3] Einarsson T., Rit. Soc. Sci. Isl. 26 (1942) 91.

[4] Bodvarsson G., J. Icel. Assoc. Eng. 35 (1950) 48; Bodvarsson G., Jokull 11 (1961) 29; Bodvarsson G., 5th Workshop Geoth. Reservoir Eng., Stanford, California (1979). [5] Bodvarsson G., J. Volc. Geoth. Res. 19 (1983) 255

[6] Lister C.R.B., Geoph. J. Royal Astr. Soc. 39 (1974) 465; Lister C.R.B., Proc. 2nd UN Symp. Devel. \& Uses of Geoth. Resources 1 (1976) 459; Lister C.R.B., Tectonoph. 37 (1977) 203.

[7] Björnsson H. et al., Nature 295 (1982) 580.

[8] Spiess F.N. et al., Science 207 (1980) 1421.

[9] White D.E., Geol. Soc. Am. Bull. 68 (1957) 1637; White D.E., U.S. Geol. Surv. Prof. Paper 458-C (1968)109.

[10] Irvine T.N., Can. J. Earth Sci. 7 (1970) 1031.

[11] Stefansson V. \& Björnsson S., Am. Geoph. Un. Geodynamic Ser. 8 (1982) 123. [12] Fournier R.O., in Geothermal Systems, Eds.: L. Rybach \& L.J.P. Muffler (J. Wiley) 1981, p. 109.

[13] Fournier R.O., Geoth. Resources Council Spec. Rep. 13 (1983) 263; Muffler L.J.P. et al., Proc. Pacific Geoth. Conf. Pt. 2 (1982) 349.

[14] Straus J.M. \& Schubert G., J. Geoph. Res. 82 (1977) 325.

[15] Dunn J.C. \& Hardee H.C., J. Volc. Geoth. Res. 11 (1981) 189.

[16] Donaldson I.G., New Zeal. J. Sci. 11 (1968) 3; Sheu J.P. et al., J. Geoph. Res. 84 (1979) 7524

[17] Schubert G. \& Straus J.M., J. Geoph. Res. 82 (1977) 3411.

[18] Grant M.A. et al., Geothermal Reservoir Engineering (Academic Press) 1982, p. 369. 